Como citar: Neto, Z. G. S., Bubols, M. N., Irigaray, T. Q. (2021). Percepção sobre a mediação judicial familiar pelos pais em casos de disputa de guarda de filhos. PSI UNISC, 5(1), 144-157. doi:

10.17058/psiunisc.v5i1.14950

\title{
Percepção sobre a mediação judicial familiar pelos pais em casos de disputa de guarda de filhos
}

\author{
Percepción de la mediación judicial familiar por parte de los padres en disputas de \\ custodia de los hijos
}

\section{Perception about family judicial mediation by parents in child guarantee cases} \author{
ORCID: 0000-0002-1809-1743
}

E-mail: zeno.souza@fcr.edu.br

Zeno Germano de Souza Neto

Milena Nardini Bubols

Pontifícia Universidade Católica do Rio Grande do Sul (PUCRS), Porto Alegre - RS/Brasil ORCID: 0000-0002-5558-4985

E-mail: milenabubols@gmail.com

Tatiana Quarti Irigaray

Pontifícia Universidade Católica do Rio Grande do Sul (PUCRS), Porto Alegre - RS/Brasil ORCID: 0000-0002-6824-5448

E-mail: tatiana.irigaray@pucrs.br

\begin{abstract}
Resumo
Este artigo apresenta uma pesquisa que teve o objetivo de identificar como os pais que participaram de mediação judicial em casos de guarda de filho compreendem o processo de mediar conflitos e os resultados desse trabalho. Participaram 22 indivíduos que estiveram em litígio em razão da guarda de seus filhos nas Varas de Família do Tribunal de Justiça de Rondônia e que fizeram um acordo a partir do trabalho de mediação judicial dos conflitos. Para a coleta de dados, foi utilizada uma entrevista semiestruturada. Os dados foram tratados pelo método de Análise de Conteúdo e analisados por meio da literatura sobre mediação familiar. Na análise dos dados, houve percepções da mediação como um procedimento eficaz, eficiente para trabalhar os conflitos familiares e como um atendimento recomendável para outros indivíduos. A maior parte dos dados indicou que os participantes assimilaram os objetivos da mediação, foram cooperativos e se sentiram satisfeitos com o atendimento que receberam, resultando no fim da disputa processual. Houve críticas negativas também referentes ao atendimento e aos resultados da mediação. No entanto, concluiu-se que, para a maioria dos participantes, os acordos judiciais obtidos por mediação em casos de disputas pela guarda dos filhos foram mantidos e promoveram uma melhoria da comunicação entre os pais durante a mediação.
\end{abstract}

Palavras-chaves: Mediação; Família; Resolução de conflitos.

\section{Resumen}

Este artículo presenta una investigación que tuvo el objetivo de identificar cómo los padres que participaron en la mediación judicial en casos de custodia de menores entienden el proceso de mediación de conflictos y los resultados de este trabajo. Participaron 22 personas que estaban en disputa sobre la custodia de sus hijos en los Tribunales de Familia del Tribunal de Justicia de Rondônia, Brasil, y que hicieron un acuerdo basado en el trabajo de mediación judicial de conflictos. Para la recolección de datos, se utilizó una entrevista semiestructurada. Los datos se trataron con el método de Bardin y se analizaron con la literatura sobre mediación familiar. En el análisis, hubo percepciones de la mediación como un procedimiento efectivo, considerándolo eficiente para tratar los conflictos familiares y recomendándolo a otras personas. La mayoría de los datos indicaron que los participantes asimilaron los objetivos de la mediación, cooperaron y se sintieron satisfechos con el servicio que recibieron, dando como resultado el final de la disputa procesal. También hubo críticas negativas con respecto a la 
asistencia y los resultados de la mediación, sin embargo, se concluyó que, para la mayoría de los participantes, los acuerdos judiciales obtenidos a través de la mediación en casos de custodia de menores se mantuvieron y generaron una mejora en la comunicación entre los padres. durante la mediación.

Palabras clave: Mediación; Familia; Resolución de conflicto.

\begin{abstract}
This article presents research that aimed to identify how parents who participated in judicial mediation in child custody cases understand the process of mediating conflicts and the results of that work. Participated 22 individuals who were in dispute about the custody of their children in the Family Courts of the Court of Justice of Rondônia, Brazil, and who made an agreement based on the work of judicial mediation of conflicts. For data
\end{abstract}

collection, a semi-structured interview was used. The data were treated using the Bardin technique and analyzed using the literature on family mediation. In the analysis, there were perceptions of mediation as an effective procedure, considering it efficient to deal with family conflicts and recommending it to other individuals. Most of the data indicated that the participants assimilated the objectives of the mediation, were cooperative and felt satisfied with the service they received, resulting in an end to the procedural dispute. There were also negative criticisms regarding the attendance and the results of the mediation, however, it was concluded that, for the majority of the participants, the judicial agreements obtained through mediation in child custody cases were maintained and generated an improvement in communication between parents during mediation.

Keywords: Mediation; Family; Conflict resolution.

\section{Introdução}

A mediação judicial de conflitos consiste na prática conduzida por um indivíduo qualificado no âmbito do Poder Judiciário, que visa auxiliar os envolvidos em um processo judicial a estabelecer uma comunicação a respeito das divergências vivenciadas, gerando um entendimento a respeito da resolução do litígio existente (Azevedo, 2015; Souza Neto, D’Âvila, \& Honorato, 2018). Atualmente, as situações que envolvem disputas pela guarda de filhos nas Varas de Famílias são indicadas para a prática da mediação, assim, os profissionais que atuam no sistema de justiça têm se debruçado sobre a possiblidade de mediar conflitos dessa natureza (Gonçalves, 2015).

Cada vez mais a primazia jurídica busca soluções colaborativas que atendam a ambas as partes em litígio, e assim, a mediação de conflitos tem sido cada vez mais utilizada como uma espécie de "fio condutor", tanto para a resolução dos processos judiciais, como para a promoção da cidadania e de uma cultura de paz (Souza Neto et al., 2018). A mediação começou a ser contemplada de forma sistemática pelo sistema de justiça brasileiro a partir da resolução 125 do Conselho Nacional de Justiça (Resolução $\left.n^{\circ} 125,2010\right)$ que orienta a criação de centros especializados em resolução de conflitos pelos Tribunais, enfatizando uma política de atendimento que estimula os indivíduos a buscarem a solução dos litígios por meio do diálogo e estabelecimento de acordos. Tal situação mostrou-se mais rápida e eficaz do que o trâmite normal do processo e seus resultados, uma vez que são os próprios indivíduos envolvidos e não o Juiz de Direito, que estabelecem os caminhos de resolução da conflitiva (Kammer \& Busnello, 2015).

No ano de 2015, o Brasil regulamentou a mediação através da lei $n^{\circ} 13.140 / 2015$, que passou a sustentar a prática tanto judicial, quanto extrajudicial da mediação. No ano de 2016, entrou em vigor o novo código de processo civil brasileiro, não apenas prevendo a mediação desde o início de qualquer processo na esfera civil, mas também inserindo-a, juntamente com a conciliação, como um procedimento inicial obrigatório que poderia ser colocada a qualquer tempo do trâmite processual, desde que obtenha anuência dos indivíduos envolvidos (Lei ${ }^{\circ} 13.105,2015$; Lei $\left.\mathrm{n}^{\mathrm{o}} 13.140,2015\right)$.

As vantagens da mediação como ferramenta para tratar dos conflitos familiares em oposição ao método tradicional de processos judiciais têm sido discutidas na literatura científica (Almeida, 2015; Chriso \& Cerdotes, 2016; Spengler \& Marcantônio, 
2013). Segundo esses estudos, é necessário manter e melhorar os vínculos entre os litigantes, bem como a celeridade do processo. Assim, o método de autocomposição baseado no consenso e no diálogo entre as partes, com a facilitação de um terceiro qualificado, o mediador, demonstra ser o mais indicado.

Assim, a mediação é o método ideal para conflitos que envolvem relações continuadas, como são os casos de conflitos familiares envolvendo separações e disputas de guarda de filhos. Por meio do diálogo, muitas consequências negativas são excluídas e a probabilidade de uma relação mais saudável e adequada às situações de pós-ruptura é maior. Os indivíduos têm uma maior chance de superar os conflitos em prol dos filhos (Diniz \& Malta, 2014; Gonçalves, 2015).

Estudos sobre a relevância da mediação são entendidos como necessários para maiores avanços na compreensão de sua eficácia. Pesquisas empíricas sobre a temática, que analisam tanto os níveis de aceitação e as formas de compreensão dos envolvidos em mediações familiares, quanto a eficiência e eficácia do trabalho de mediar conflitos familiares, foram realizadas em países, como Portugal (Andrade \& Bueno, 2013; Correia, 2011; Pratas, 2012), Brasil (Alves, Cúnico, Arpini, Smaniotto, \& Bopp, 2014; Chrystêllo, 2014), Itália (Molgora, Ranieri, \& Tamanza, 2014) e Estados Unidos da América (Rudd, Ogle, Hultzworth-Munroe, Applegate, \& D’Onofrio, 2015b; Rudd et al., 2015a). No Brasil, no entanto, ainda são escassos os estudos empíricos sobre o tema.

A mediação de conflitos, além de possibilitar a realização de acordos, gera a melhoria nas relações entre os indivíduos, estabelecendo uma comunicação mais saudável e diminuindo os conflitos (Molinari, 2016; Souza Neto et al, 2018). Dessa forma, o presente artigo apresenta uma pesquisa que teve como principal objetivo identificar como os indivíduos que participaram de mediação judicial em casos de guarda de filho compreendem o processo de mediar conflitos. Além disso, a pesquisa ainda investigou: a) os desfechos de acordos judiciais obtidos por mediação em casos de guarda de filhos; b) as razões que motivaram os indivíduos a participarem da mediação; c) como indivíduos que fizeram acordo por mediação judicial em casos de guarda de filhos avaliam o resultado do trabalho realizado; d) se o acordo judicial estava sendo mantido, assim como os motivos para a manutenção ou não do acordo, e; e) se houve percepção de melhora na comunicação entre as partes.

\section{Método \\ Delineamento}

O método da pesquisa apresentada foi qualitativo com delineamento transversal. A pesquisa qualitativa tem como foco os aspectos da subjetividade humana emergente por meio dos dados, não focando na generalização dos resultados (Azungah, 2018). Visa estudar, registrar, analisar e interpretar como os indivíduos constroem e atribuem significados particulares às suas experiências, necessitando, para tal, um pequeno número de participantes (Gray, 2012).

\section{Participantes}

Foram incluídos como população desse estudo todos os processos das quatro Varas de Familia da Comarca de Porto Velho no Estado de Rondônia, que tinham mediação judicial de guarda de filhos e que geraram um termo de acordo. Inicialmente, totalizaram 34 processos judiciais, resultando em 68 possíveis participantes. Foram considerados como critérios de inclusão dos participantes: a) ter mais de 18 anos; b) ser pai ou mãe, biológico ou afetivo, das crianças e/ou adolescentes envolvidas nos litígios, mesmo que apenas um deles aceitasse participar da pesquisa. Foram excluídos os indivíduos que apresentaram alguma deficiência física ou sensorial que os impedissem de responderem a entrevista e aos instrumentos ( $n=3$ indivíduos), indivíduos que participaram de mediação, mas que não eram pais biológicos, sendo avós ou tios ( $n=7$ indivíduos), assim como as mediações que não geraram acordo ( $n=21$ processos). 
Assim, a amostra final foi composta por 22 indivíduos que estiveram em litígio sobre a guarda de seus filhos nas Varas de Família do Tribunal de Justiça de Rondônia e que fizeram um acordo a partir do trabalho de mediação judicial dos conflitos, entre os anos de $2013 \mathrm{e}$ 2018.

\section{Instrumentos}

Foi realizada uma entrevista semiestruturada, composta por 11 itens que investigaram: a) a participação no atendimento de mediação de conflitos no Tribunal de Justiça; b) a motivação para participar da mediação; c) a opinião dos participantes sobre a mediação; d) a percepção dos participantes quanto ao conflito e à comunicação com o outro genitor antes e depois da mediação; e) a percepção dos participantes quanto aos resultados da mediação para os filhos; e f) a recomendação da mediação para outros indivíduos.

\section{Procedimentos \\ Coleta de Dados}

O contato com os participantes envolvidos em mediações foi facilitado pela equipe do serviço psicossocial das Varas de Família. O contato foi telefônico e realizado por um psicólogo e uma equipe de graduandos em Psicologia, treinados previamente. Agendadas as entrevistas, cada encontro teve a duração de aproximadamente uma hora e meia, e foi realizada individualmente em diversos locais, já que os próprios indivíduos apontavam o local de sua preferência. Assim, as entrevistas ocorreram nas residências dos participantes, nos seus locais de trabalho ou em uma clínica escola de psicologia.

\section{Condições éticas}

O presente estudo foi aprovado pelo Comitê de Ética em Pesquisa (CEP) da Pontifícia Universidade Católica do Rio Grande do Sul (PUCRS), sob o número CAAE 71027917.2.0000.5336. Os participantes que aceitaram participar do estudo assinaram o Termo de Consentimento Livre e Esclarecido
(TCLE) de acordo com o previsto na resolução $\mathrm{n}^{\text {o }}$ 510/2016 do Ministério da Saúde sobre pesquisa com seres humanos.

\section{Análise dos dados}

As respostas da entrevista semiestruturada foram categorizadas de acordo com as etapas da análise de conteúdo (Bardin, 2009). As categorias foram definidas à posteriori, de acordo com a frequência que os temas surgiram nas entrevistas e analisadas a partir de teorias sobre mediação de conflitos familiares. Os participantes e suas respostas estão denominados como P1 a P22.

Foram seguidas as etapas metodológicas tal como propostas por Bardin (2009). Primeiramente foi realizada a préanálise do material por meio da leitura flutuante, seleção e organização das respostas apresentadas por meio da representatividade, homogeneidade e pertinência ao tema investigado por meio das perguntas do questionário.

Seguindo as orientações apresentadas por Bardin (2009), a exploração do material levou a definição de critérios expressivos para a definição posterior das categorias. A interpretação dos dados aconteceu por meio da inferência, contemplando tanto a análise temática quanto uma leitura vertical dos enunciados (análise da enunciação), aonde se buscou compreender também aspectos não verbais e gestuais.

\section{Resultados e Discussão}

A amostra final foi composta por 22 participantes. A equipe contatou 49 indivíduos ao todo, mas 29 se recusaram a participar da pesquisa. A idade mínima informada dos filhos foi de dois anos e a máxima foi de 12 anos. As características sociodemográficas dos participantes podem ser consultadas na Tabela 1. Conforme se pode verificar, a média de idade dos participantes caracteriza-os como adultos jovens. A maioria vivia em união estável, tendo ensino médio completo e trabalho formal, com uma renda de um a dois salários mínimos. 
Tabela 1

Caracterização sociodemográfica dos participantes.

\begin{tabular}{llccc}
\hline Variáveis & $\boldsymbol{n}$ & $\mathbf{\%}$ & $\boldsymbol{M}$ & $\boldsymbol{D P}$ \\
\hline Idade (anos) & 22 & 100 & 31,59 & 7,96 \\
\hline Estado Civil & & & & \\
Solteiro(a) & 4 & 18,20 & \\
Casado(a) & 5 & 22,70 & \\
Divorciado & 6 & 27,30 & \\
União Estável & 7 & 31,80 & & \\
\hline Sexo & & & \\
\hline Masculino & 11 & 50,00 & \\
Feminino & 11 & 50,00 & \\
\hline Escolaridade & & & \\
\hline Ensino Fundamental Incompleto & 3 & 13,60 & \\
Ensino Fundamental completo & 2 & 9,10 & \\
Ensino Médio Completo & 11 & 40,00 & \\
Ensino Superior Completo & 6 & 27,30 & \\
\hline Atividade Profissional & & & \\
\hline Trabalho Informal & 4 & 18,20 & \\
Trabalho Formal & 13 & 59,10 & \\
Desempregado & 2 & 9,10 & \\
Dona de Casa & 3 & 13,60 & \\
\hline Renda* & & & \\
\hline Sem renda & 3 & 13,60 & \\
Menos de um salário mínimo & 2 & 9,10 & \\
Um a dois salários mínimos & 12 & 54,50 & \\
Três ou mais salários mínimos & 5 & 22,70 & \\
\hline Sario & &
\end{tabular}

Nota. $*$ Salário mínimo brasileiro de $\mathrm{R} \$ 998,00$ reais.

É importante ressaltar que os casos abordados no artigo se trataram de mediações judiciais. Uma mediação judicial é aquela realizada em âmbito jurídico relacionada a um processo judicial em curso (Souza Neto et al., 2018). No que se refere à mediação judicial, pôde-se perceber que os indivíduos que enfatizaram os aspectos legais como razões para a mediação, não estavam imbuídos da consciência do que é a mediação e quais são seus reais objetivos. Assim, as respostas dadas por esses participantes sinalizaram suas dificuldades quanto ao real objetivo e função da mediação (Busnello \& Santos Sobrinho, 2015).

As respostas foram registradas e posteriormente analisadas conforme o método de Análise de Conteúdo, a partir do qual se configuraram três categorias principais: 1) Predisposição para a mediação e facilitação ao diálogo; 2) A Mediação é um Procedimento Eficaz? e 3) Limitações e Críticas: diferentes percepções acerca do processo de mediação. A seguir, cada categoria será apresentada e discutida:

\section{1) Predisposição para a mediação e facilitação ao diálogo.}

Por meio das entrevistas, evidenciou-se a disposição dos participantes em tentar dialogar com outros familiares, motivados pela busca do bem estar dos filhos: "Fiz pelo meu filho" (P14), "Fiz pensando no meu filho" (P16), "Fiz uma tentativa de aproximar pai e filho" (P19) e "Percebia a falta de atenção do pai... A mediação melhorou o diálogo entre nós, estamos pensando mais na nossa filha" (P1). Assim, a mediação contribuiu para a promoção do diálogo entre os envolvidos, o que gerou consequências positivas nas crianças: “... foi muito boa para o diálogo, porque as brigas diminuíram" (P8), "Foi boa porque ajudou a dialogar e diminuir os conflitos" (P9), "Foi muito boa, ajudou na nossa convivência com as crianças." (P14). As respostas corroboram com a literatura a respeito da importância da mediação na promoção do diálogo, na convivência entre os indivíduos e na diminuição do conflito (Correia, 2011; Parkinson, 2005). 
A intenção dos participantes em viabilizar uma forma de aproximação entre os filhos e o genitor, ou ainda, aceitar a mediação por entender que é bom para os filhos conviver com o outro membro familiar, demonstra o quanto a mediação passou a ter uma representação diferente do que se entende habitualmente por uma audiência. Este dado corrobora com a literatura que refere a mediação como um procedimento informal, confidencial e flexível, contrastando com as audiências regidas por normas jurídicas formais (Parkinson, 2005).

O novo código de processo civil no artigo 334 (Lei $\mathrm{n}^{\circ} 13.105$, de 16 de março de 2015) se refere à mediação como audiência. No entanto, se identifica na mediação um caráter de informalidade, pois representa a possibilidade de um atendimento diferenciado daquilo que se espera no âmbito jurídico, podendo se tratar de temas específicos de um processo judicial (Parkinson, 2005; Souza Neto et al., 2018).

A maioria dos participantes $(n=14)$ referiu que, antes da mediação, não havia nenhuma forma de diálogo, o que contribuía para brigas entre os envolvidos, como referem P10 e P14 "Nós brigávamos e discutíamos muito. Não tinha muita conversa", "Era ruim, muitas brigas". Nesses casos, a mediação serviu para facilitar um diálogo que já era desejado pelos participantes, mas que sozinhos não conseguiam ter: "A gente brigava. Eu brigava muito com a mãe das crianças (...) eu queria poder dialogar, ter consenso" (P6). Assim, viabilizar o diálogo entre as partes e construir um entendimento sobre a disputa traz alívio para os indivíduos, além de possibilitar o encerramento do processo judicial (Souza Neto et al., 2018). O acordo não é sinônimo de sucesso pleno da mediação, uma vez que deverá entrar em questão o engajamento dos envolvidos para que esse acordo obtido seja mantido e/ou transformado positivamente, refletindo em maturidade e responsabilidade das partes (Molinari, 2016).

Por outro lado, o participante P22 referiu que: "A comunicação ficou pior depois da mediação, não nos falamos mais", manifestando que a mediação contribuiu para dificultar o diálogo entre ele e sua excompanheira, já que nem sempre a mediação é bem-sucedida. O participante $\mathrm{P} 22$ referiu que a mãe não estava cumprindo o acordo e que por isso a relação entre eles piorou após a mediação. Quando uma das partes não cumpre o acordo, é possível que o nível de conflito entre os indivíduos fosse muito alto e o acordo acabou sendo realizado sem o devido trabalho de melhorar a comunicação entre os envolvidos, o que leva ao descumprimento do conteúdo acordado (Azevedo, 2015; Parkinson, 2007).

Ressalta-se que alguns indivíduos
aceitam acordos sem estarem realmente
confortáveis com essa posição na sessão de
mediação. Principalmente em mediações
judiciais, isso pode ocorrer uma vez que o
ambiente judiciário e a condução da mediação
podem estimular a ideia de que o acordo é uma
obrigação na mediação. Tais situações também
sinalizam a importância da capacitação dos
mediadores para a condução adequada de seu
trabalho (Sales \& Chaves, 2015).

No Brasil não é uma prática dos mediadores incluir crianças nas mediações. Já em Portugal tem sido frequente a inserção de filhos adolescentes no processo, pois diferente da criança, o adolescente mostra um nível de maturidade que o permite se posicionar diante dos conflitos de forma mais clara, contribuindo para a mediação (Molinari, 2016). No presente artigo, as crianças mais velhas tinham 12 anos, portanto, nenhuma delas participou efetivamente das mediações.

Apesar dos filhos não terem participado diretamente das mediações, dentre os 22 participantes, quatro responderam que perceberam mudanças negativas no comportamento dos filhos após o procedimento. $\mathrm{P} 4$ referiu que a criança reclama da mãe, não querendo estar com ela, P8 alega que a criança não consegue se aproximar do pai porque este não estimula. Já P11 reclama que a filha sente as diferenças na educação lhe dada pelos pais, enquanto P19 refere que os filhos 
ficaram mais "rebeldes" e "desobedientes".

Do total de entrevistados, dois deles (P9 e P19) não chegaram a um acordo e nem conseguiram estabelecer um diálogo com o outro genitor o que pode indicar que o nível do conflito entre as partes já era elevado e se estendeu às crianças. P4 e P11 conseguiram entrar em acordo, porém observaram prejuízos no comportamento dos filhos. A piora do comportamento dos filhos pode dizer respeito ao que tudo isso representou na vida dos filhos. Por exemplo, o término da mediação, com o acordo sendo firmado, pode gerar nos filhos a ideia de possível irreversibilidade de retorno dos pais, caso ainda fantasiem com um resgate da relação conjugal. Ainda, pode dizer respeito á expressão de possível sofrimento por ocasião da situação familiar vivenciada, independente do trabalho de mediação. Pode-se também compreender que o relacionamento entre os pais permaneceu ruim mesmo após o acordo, evidenciando que apenas o acordo não é suficiente para a mediação ser frutífera.

Sete participantes do estudo enfatizaram uma reação indiferente dos filhos ao processo de mediação. Já os demais $(n=11)$ referiram que, além de realizarem um acordo, perceberam a melhoria da comunicação entre os familiares e comportamentos mais saudáveis de seus filhos, como a aproximação e convivência com ambos os pais e melhora de rendimento na escola, aspectos considerados positivos por meio de uma mediação que consegue trabalhar com foco no desenvolvimento do diálogo entre os envolvidos (Chrystêllo, 2014; Diniz \& Malta, 2016; Molinari, 2016; Souza Neto et al., 2018).

Ainda sobre as relações familiares, outro aspecto que se destacou nas entrevistas foi uma possível negação da situação conflitiva familiar. Isso se tornou evidente, pois dentre os 22 entrevistados, cinco responderam que não havia conflito antes da mediação, isto é, que pelo fato de não encontrarem o outro familiar (pai ou mãe) estava tudo bem. $\mathrm{O}$ resultado do processo de mediação para esses sujeitos foi: três deles não chegaram a um acordo, um considerou a mediação apenas parcialmente satisfatória, enquanto que o quinto participante chegou a um acordo com a outra parte, mas sem melhoria na comunicação entre os membros.

A importância da comunicação nas relações humanas para que se desenvolvam de forma mais saudável tem sido enfatizada nos últimos anos, nos estudos de Rosenberg (2006) sobre comunicação não violenta. Na esfera específica das relações familiares, existem estudos que sinalizam a importância da comunicação entre os membros da família como um fator determinante de equilíbrio ou de ausência deste (Boechat, Cabral, \& Souza, 2015; Cézar-Ferreira, 2009; Teixeira, Froes, \& Zago, 2006).

Conforme refere Molinari (2016), a mediação busca aproximar os indivíduos por meio do diálogo. Esse aspecto foi percebido na fala dos participantes que referiram que a mediação contribuiu para a melhora na comunicação entre eles. As respostas apontam uma melhora na comunicação entre os conflitantes e não apenas a criação de um acordo formal, que por si só, não garante o êxito da mediação como um todo, ou seja, apenas realizar o acordo não significa que ele será cumprido.

Os participantes referiram benefícios como o bem estar dos filhos e o estabelecimento de uma relação mais saudável entre os genitores. Portanto, a viabilização do diálogo entre as partes por meio do processo de mediação demonstra que, apesar de as Varas de Família serem um espaço judicial em que os indivíduos tendem ao conflito e à disputa, com pouca disposição para atos conciliatórios, também pode ser um espaço de mudança $\mathrm{e}$ conciliação (Miranda Júnior, 2010; Shine, 2010).

\section{2) A Mediação pode ser um procedimento eficaz?}

Os participantes da pesquisa foram apenas mediandos que construíram um acordo e por isso existe um aspecto importante a ser considerado; de que pessoas que fizeram um acordo tendem a perceber o procedimento 
como algo positivo. Assim, foi percebido que a participação na mediação tinha como objetivo o diálogo e a busca de acordos, corroborando com a literatura que aponta como sendo esses os verdadeiros objetivos da mediação de conflitos (Kammer \& Busnello, 2015; Souza Neto et al., 2018). A mediação bem-sucedida pode realmente ajudar os indivíduos a melhorar aspectos relacionais entre si, como o diálogo, os vínculos e a convivência com os fillhos, além de apresentar melhoria na qualidade de vida e nos relacionamentos interpessoais nas situações de divergências (Azevedo, 2015; Souza Neto et al., 2018).

Os participantes referiram benefícios em relação ao processo de mediação: " $A$ mediação me fez querer dar o melhor aos meus filhos" (P14) e "O acordo me fez bem" (P19). Além disso, foi identificado que o processo gerou uma melhoria do diálogo e estabelecimento de uma relação saudável entre as partes, além de contribuir para o entendimento mútuo e bem estar dos filhos, conforme ilustrado pelas falas: "Melhorou, a gente não está brigando como antes" (P8), "Melhorou, agora há mais respeito e menos cobrança" (P16). Uma hipótese de explicação para esse resultado seria de que o trabalho de mediar conflitos possibilita que relacionamentos machucados venham a ser restaurados, e consequentemente pode ocorrer a resolução de conflitos, naquelas relações em que o afeto é o principal elemento (Azevedo, 2015; Chriso \& Cerdotes, 2016; Correia, 2011). Dentre os benefícios da mediação, identificouse a importância do participante se sentir acolhido, respeitado e valorizado, conforme referido por P7: "Me senti amparada pela equipe". Isso sugere a importância do mediador oferecer um espaço em que sentimentos como esse possam se manifestar, a partir da confiança no mediador e no trabalho proposto (Azevedo, 2015; Parkinson, 2005).

De modo geral, a mediação foi avaliada de modo positivo pelos participantes, seja por tratar de questões pontuais ou de questões de cunho jurídico. Dos 22 indivíduos que responderam à pesquisa, quatro não gostaram do resultado da mediação, mas somente dois não recomendariam a mediação a outros indivíduos. Pode-se destacar que a mediação foi percebida positivamente pela maioria dos participantes exemplificada em falas como: "ajuda a resolver a questão da pensão" (P5); "é bom para garantir o direito dos filhos" (P20); "é importante pra gente poder conversar" (P1); "porque pode pôr fim a um conflito" (P4); "é bom, traz paz" (P7); "ajuda a tentar resolver as brigas" (P19).

Houve casos em que os participantes entenderam a mediação como sendo parcialmente eficaz $(n=3)$. Percebeu-se nas falas dos participantes que as respostas se direcionaram em torno de conteúdos subjetivos, como antipatia pelos mediadores, a sensação de ser forçado a um acordo e o incômodo com o próprio conteúdo geral da mediação. No que se refere a possíveis falhas na mediação, alguns participantes $(n=3)$ responderam inclusive que o diálogo piorou após a mediação. Nesse caso, tratou-se das mediações infrutíferas em que não foi possível o trabalho de apaziguamento dos conflitos e tampouco se chegou à construção de um entendimento entre as partes. Nesse sentido, não foram referidos elementos suficientes para que se possam afirmar que isso ocorreu devido a uma condução inadequada da mediação por parte do mediador, podendo ser por esse motivo, ou ainda, devido ao alto nível do conflito existente entre os indivíduos envolvidos.

Quando existem relações em conflito, ocorre uma progressiva escalada desses conflitos, fruto de um movimento circular vicioso envolvendo os indivíduos na dinâmica ação/reação. Cada reação violenta diante de uma ação violenta acaba se tornando mais severa do que a ação que a precedeu, criando assim novos pontos de conflito. As teorias em mediação denominam essa situação como espiral do conflito. Nesses casos, quando a espiral do conflito ainda está elevada, é contraindicada a mediação (Azevedo, 2015).

Ainda em relação a falhas no processo, apenas dois participantes não se sentiram satisfeitos com o trabalho realizado pela equipe 
de mediação e não a indicariam para outros indivíduos. Essa falha parece estar diretamente relacionada ao uso de dispositivos de controle quanto ao cumprimento ou não dos acordos realizados, conforme refere P11: "é muito válido [o processo de mediação], mas não foi eficaz, pois o pai não está cumprindo o acordo". Outra falha referida pelos participantes diz respeito à inalterada situação como um todo, sugerindo aumento dos aspectos negativos nas relações: "Só estamos seguindo as regras. Não mudou em nada a nossa comunicação" (P10); "Não mudou nada. A gente não conversa direito" (P13); "Piorou. $O$ pai se afastou de vez. Não tem contato, não aparece" (P5) e "Não temos diálogo. Estamos mais afastados agora" (P20).

As falas acima mostraram situações em que a espiral de conflito ainda se manteve alta mesmo após o trabalho da mediação. Aqui mais uma vez, pode-se refletir, tanto a respeito das dificuldades apresentadas pelos pais previamente à mediação, como também sobre as formas como as sessões foram conduzidas pelos mediadores. É possivel que nestes casos também o trabalho acabou mais direcionado a efetivação de um acordo para por fim ao processo judicial, do que em aprofundar a necessidade de melhoria da relação entre pai e mãe.

\section{3) Críticas e Limitações: diferentes percepções acerca do processo de mediação}

Dentre as críticas e limitações recebidas sobre o processo de mediação, os participantes apontaram que o fracasso no seu processo de mediação ocorreu basicamente por duas questões: quebra da imparcialidade do mediador e o descumprimento do acordo pelo outro genitor. $\mathrm{O}$ primeiro ponto diz respeito à uma possível deficiência do mediador, que perdendo sua imparcialidade, perde um dos pilares de sustentação da mediação (Kammer \& Busnello, 2015), o que fica evidente nas falas: "O trabalho da equipe me deixou frustrado. Só acreditavam na mãe" (P4); "Achei falha. Não foi eficaz, só visualiza o lado da mãe" (P2), "Me senti incomodado com o teor das conversas" (P12); "Não gostei do jeito da psicóloga" (P4). A imparcialidade é um dos pilares da mediação para que o trabalho se mantenha e se conclua no sentido de ajudar os indivíduos a dialogarem. Não existindo imparcialidade, é comum que ocorra, nos envolvidos no atendimento, o sentimento de estar sendo preterido, perda de envolvimento e de espontaneidade.

\section{Como ressaltam Villaluenga e Cartujo} (2010), o apoio e a imparcialidade fortalecem os indivíduos em mediação e contribuem para que os mediandos se tornem mais confiantes e dispostos a cooperar para encontrar soluções para seus conflitos. Assim, a imparcialidade e a confidencialidade - outro pilar da mediação são necessários para a construção de uma relação de confiança entre todos os participantes da mediação. A percepção da perda da imparcialidade do mediador impediu que o indivíduo se vinculasse ao mediador e ao trabalho de mediar, o que culminou na falha da mediação como um todo.

Percebeu-se que os sentimentos negativos manifestados pelos participantes estavam conectados com a perda da imparcialidade do mediador, o que é um prejuízo grave para a mediação. Assim, faz-se importante que o mediador ofereça uma abertura adequada aos participantes, explicando claramente de forma didática como é realizado o trabalho da mediação, buscandose certificar de que o indivíduo realmente entendeu as características de todo o processo. A clareza do processo de mediação é fundamental para que ele seja eficaz (Azevedo, 2015).

Sobre o segundo ponto, o descumprimento do acordo pelo outro genitor, identificou-se que o entendimento foi mantido em 12 casos $(54,5 \%)$, enquanto que seis participantes $(27,3 \%)$ responderam que não. Quatro participantes $(18,2 \%)$ referiram que o acordo estava sendo parcialmente mantido. Esses resultados podem estar relacionados a duas questões: por um lado, o consenso pode não estar sendo cumprido, pois a outra parte não aceitou a composição desde o início da 
mediação, conforme fica evidente na fala "Considero a mediação parcialmente eficaz, pois me senti meio forçado a aceitar um acordo" (P4); por outro lado, pode estar havendo um descumprimento de uma das partes acordadas, já que não há uma forma de controle acerca das condutas adotadas pelas partes após a mediação, conforme ilustra a fala a seguir: "O pai é ausente. Não mudou nada" (P19).

Houve frustração nas falas dos participantes que perceberam não terem se beneficiado da mediação, procurando responsabilizar os profissionais pela falha e não pelas suas possíveis dificuldades ou as da outra parte, que não estão cumprindo com o acordado. Nesse aspecto, pode-se compreender que a mediação tenha sido malconduzida pelos mediadores, mas também se pode pensar em outros elementos que possam ter interferido no processo, como uma resistência dos participantes em mudar as suas condutas e os seus modos de se relacionarem, assim como dificuldades em manter as combinações acordadas e deixar de ser influenciado pela representação punitiva que o judiciário possui. A partir desses resultados, pôde-se verificar que a adesão à mediação dependia da motivação dos envolvidos, juntamente com um baixo nível de conflito.

A partir das respostas dos participantes, pode-se entender que houve um manejo inadequado do procedimento por parte de alguns mediadores. Alguns participantes afirmaram que não compreenderam os objetivos da mediação, confundindo-a com alguma espécie de avaliação: "Fiquei indignado com a justiça não ir verificar a situação de negligência da criança" (P2). Este relato pode sugerir que existe uma dificuldade dos profissionais em abordar e conduzir o procedimento de mediação de forma empática e sensível às demandas da população.

O perfil dos mediadores é objeto de atenção na literatura científica (Cúnico, Arpini, Mozzaquatro, Silva, \& Bopp, 2012; Dias \& Souza, 2015; Gruspun, 2000; Muller, 2007; Melo, 2013; Rezende, 2015; Serrano, 2008;
Montoya Sánchez, 2010). De modo geral, se compreende que habilidades como capacidade empática, capacidade de escuta, sensibilidade e conhecimento interdisciplinar, além de uma postura de boa-fé, conduta ética e condição emocional para lidar com os sentimentos do outro e o que esses sentimentos suscitam no mediador são essenciais para que o mediador consiga realizar seu trabalho. A ausência de algumas dessas características no mediador torna o trabalho de mediar mais difícil ou mesmo impossível (Trindade \& Molinari, 2015). Estudos sugerem que em casos de qualquer conduta antiética dos mediadores, o vínculo com os mediandos tende a ser perder e prejudicar, senão impedir, a mediação (Aréchaga, Brandoni, \& Finkelstein, 2004; Parkinson, 2005).

Por fim, identificou-se que, em alguns casos, a mediação não só foi falha, como também contribuiu para uma piora na relação entre as partes. Nesse sentido, pode-se salientar que quando o nível de conflito é muito alto entre os indivíduos envolvidos no conflito, a mediação pode não ser possível (Azevedo, 2015). É possível também que nas mediações percebidas como falhas, o esclarecimento quanto às regras e papéis do mediador e dos mediandos não tenham sido devidamente realizados, assim como a conduta parcial do mediador tende a acirrar o conflito vivenciado pelos mediandos.

Entre os quatro indivíduos que não perceberam mudanças positivas e nem negativas com a mediação, sobretudo no que se refere à comunicação com o outro, três deles consideraram a mediação realizada como positiva e todos os quatro fizeram acordos em suas mediações. Porém, nesses casos, a mediação conseguiu apenas atingir o acordo, e não o objetivo de reestabelecer a comunicação saudável entre os indivíduos. Nesse contexto específico da mediação judicial, o acordo que encerra o processo ganha caráter de êxito, porém pode não ser eficaz, aspecto que é diferente de mediações realizadas em espaços extrajudiciais (Germano, 2017).

\section{Considerações Finais}


A partir do estudo realizado, foi possível verificar que a mediação possibilitou que os pais envolvidos em processos judiciais na área de família fossem escutados sem o objetivo de uma avaliação psicossocial ou jurídica, mas sim, como tentativa de resolução pacífica das divergências por meio do diálogo. Para a maioria dos participantes, os acordos judiciais obtidos por mediação em casos de guarda de filhos foram mantidos. As razões que motivaram os indivíduos a participar da mediação foram o diálogo e a busca do acordo com o outro genitor e a avaliação do resultado obtido com a mediação foi positiva. Os acordos foram mantidos principalmente pelas mudanças ocorridas por meio da melhoria da comunicação entre os pais durante a mediação, o que levou a uma percepção positiva quanto à comunicação entre as partes.

As críticas apontadas por alguns dos pais foram no sentido de provável perda de imparcialidade por parte do(a) mediador(a), falhas na condução do trabalho a ponto de não o tornar claro ao participante e a sensação de obrigatoriedade em realizar um acordo. Tais percepções limitadoras do alcance possivel da mediação judicial, incidiram sobre a avaliação do resultado para alguns desses pais que não a recomendariam para outras pessoas. As limitações encontradas neste estudo servem também como referência para aspectos que precisam de constante atenção e aperfeiçoamento pelos estudiosos da área e pelos próprios mediadores.

Por fim, entendeu-se que a mediação proporciona um atendimento de qualidade diferenciada dentro do Judiciário e que, quando alcança seu objetivo, proporciona que o litígio processual seja mais rapidamente resolvido, além de gerar bem estar e favorecer a qualidade de vida dos participantes e de seus filhos. A partir disso, a mediação necessita de maior divulgação quanto a seus objetivos e possíveis benefícios, seja na esfera do Poder Judiciário, seja em qualquer outro campo de relações humanas. Para tal, sugere-se que sejam realizadas outras pesquisas empíricas, que aprofundem o estudo das características da mediação e seus efeitos nos indivíduos atendidos, além de estudos envolvendo os mediadores, para a compreensão das possíveis dificuldades na realização da mediação.

\section{Referências}

Almeida, T. (2015). A mediação familiar no contexto da guarda compartilhada. Recuperado de https://mediare.com.br/amediacao-familiar-no-contexto-da-guardacompartilhada/

Alves, A. P., Cúnico, S. D., Arpini, D. M., Smaniotto, A. C., \& Bopp, M. E. T. (2014). Mediação familiar: possibilitando diálogos acerca da guarda compartilhada. Revista Pesquisas e Práticas Psicossociais, 9(2), 193-201. Recuperado de http://seer.ufsj.edu.br/index.php/revista_pp p/article/view/927

Andrade, J. C., \& Bueno, E. M. (2013). Guarda compartilhada e mediação familiar: Um estudo exploratório no fórum de Mogi Mirim-SP. Universitas, 6(10), 51-72. Recuperado de http://www.revistauniversitas.inf.br/index.p $\mathrm{hp} /$ UNIVERSITAS/article/view/15

Aréchaga, P., Brandoni, F., \& Finkelstein, A. (2004). Acerca de la clínica de mediación: Relatos de casos. Colección Visión Compartida. Buenos Aires: Librería Histórica.

Azevedo, A. G. (2015). Manual de Mediação Judicial. Recuperado de

https://www.cnj.jus.br/wpcontent/uploads/2015/06/f247f5ce60df2774 c59d6e2dddbfec54.pdf

Azungah, T. (2018). Qualitative research: deductive and inductive approaches to data analysis. Qualitative Research Journal, 18(4), 383-400. doi: 10.1108/QRJD-18-00035

Bardin, L. (2009). Análise de conteúdo (Edição revista e ampliada). Lisboa: Editora 70. 
Boechat, I. T., Cabral, H. L. T. B., \& Souza, C. H. M. (2015). A comunicação da família caracterizada pela pseudomutualidade e pelo duplo vínculo. Recuperado de http://www.fsj.edu.br/transformar/index.ph p/transformar/article/view/42

Busnello, S. J., \& Santos Sobrinho, E. O. (2015). A função social da mediação. Revista Eletrônica Direito e Política, 10(3), 1558-1582. Recuperado de http://www.univali.br/direitoepolitica ISSN 1980-7791.

Cézar-Ferreira, V. V. A. M. (2009). A comunicação da família no Judiciário. Recuperado de https://www.redalyc.org/pdf/1394/1394224 10006.pdf

Correia, M. J. S. F. (2011). Mediação familiar: Um contributo para a promoção da relação entre pais em desacordo (Dissertação de Mestrado). Universidade de Açores, Portugal. Recuperado de https://docplayer.com.br/8686419Universidade-dos-acores-mediacaofamiliar-um-contributo-para-a-promocaoda-relacao-entre-pais-em-desacordo.html

Cúnico, S. B., Arpini, B. M., Mozzaquatro, C. D. O., Silva, M. L., \& Bopp, M. E. T. (2012). Psicologia e mediação familiar em um núcleo de assistência judiciária. Boletim de Psicologia, 62(137), 141-154.

Recuperado de http://pepsic.bvsalud.org/scielo.php?script= sci_arttext\&pid=S000659432012000200004

Chrystêllo, A. A. C. S. (2014). Os menores e a mediação familiar (Dissertação de Mestrado). Universidade Autônoma de Lisboa, Portugal.

Chriso, C. M., \& Cerdotes, A. (2016). A guarda compartilhada e a mediação familiar como forma de reestruturar os partícipes do núcleo familiar. In: XVII Seminário Nacional de demandas sociais e políticas públicas na sociedade contemporânea. II Mostra nacional de trabalhos científicos. UNISC. Recuperado de https://online.unisc.br/acadnet/anais/index.p hp/snpp/article/view/14699

Dias, F. A., \& Souza, J. L. (2013). O mediador (perfil, atuação e ética) na resolução dos conflitos. Revista Jurídica (FURB), 17(34), 225-251. Recuperado de https://gorila.furb.br/ojs/index.php/juridica/ article/view/4059

Diniz, H. C., \& Malta, S. C. F. (2016). Mediação de conflitos familiares: possíveis contribuições. Synthesis Revista Digital FAPAM, 5(5), 70-94. Recuperado de https://periodicos.fapam.edu.br/index.php/s ynthesis/article/view/82

Germano, Z. (2017). Psicologia Jurídica e Psicanálise: Reflexões teóricas e práticas. São Paulo, SP: Baraúna.

Gonçalves, A. M. (2015). A mediação como meio de resolução de conflitos familiares. Recuperado de http://www.pucrs.br//wpcontent/uploads/sites/11/2018/09/amanda_g oncalves.pdf

Gray, D. E. (2012). Pesquisa do mundo real. Porto Alegre, RS: Penso.

Gruspun, H. (2000). Mediação Familiar - O mediador e a separação de casais com filhos. São Paulo, SP: LTR.

Kammer, I., \& Busnello, S. J. (2015). O uso da mediação de conflitos como solução nas lides contratuais. Anais do Congresso Catarinense de Direito Processual Civil. Recuperado de https://siaiap32.univali.br/seer/index.php/ac $\underline{\mathrm{cdp}}$

Lei $n^{\circ} 13.105$, de 16 de março de 2015. Código de Processo Civil. Recuperado de http://www.planalto.gov.br/ccivil_03/_ato2 015-2018/2015/lei/113105.htm

Lei $n^{o} 13.140$, de 26 de junho de 2015. Dispõe sobre a mediação entre particulares como meio de solução de controvérsias e sobre a autocomposição de conflitos no âmbito da administração pública; altera a Lei $n^{\circ}$ 9.469, de 10 de julho de 1997, e o Decreto ${ }^{\circ}$ 70.235 , de 6 de março de 1972; e revoga o $\S 2^{\circ}$ do art. $6^{\circ}$ da Lei $n^{\circ} 9.469$, de 10 de julho de 1997. Recuperado de http://www.planalto.gov.br/ccivil_03/_ato2 $\underline{\text { 015-2018/2015/lei/113140.htm }}$

Melo, K. A. L. (2013). Mediação de conflitos familiares: Relação entre os saberes da psicologia e do direito no campo jurídico (Dissertação de Mestrado). Universidade 
Federal de Pernambuco, Pernambuco, Brasil. Recuperado de

http://repositorio.ufpe.br/handle/123456789 $\underline{10138}$

Miranda Júnior, H. C. (2010). Um psicólogo no Tribunal de Justiça: A prática na interface entre Direito e Psicanálise. Belo Horizonte, BH: Arte Sã.

Molgora, S., Ranieri, S., \& Tamanza, G. (2014). Divorce and coparenting: A qualitative study on family mediation in Italy. Journal of Divorce \& Remarriage, 55(4), 300-314. doi: $\underline{10.1080 / 10502556.2014 .901854}$

Molinari, F. (2016). Mediação de conflitos e alienação parental: Fundamentos teóricos e práticos. Porto Alegre, RS: Imprensa Livre.

Montoya Sánchez, M. Á. (2010). Mediación y Terapia o de la Forma de Tratar Integralmente el Conflicto de Familia. Revista Trabajo Social, (9). Recuperado a partir de

https://revistas.udea.edu.co/index.php/revist raso/article/view/5279

Muller, F. G. (2007). Competências profissionais do mediador de conflitos familiares (Dissertação de Mestrado). Universidade de Santa Catarina, Santa Catarina, Brasil.

Parkinson, L. (2005). Mediación familiar teoria y práctica: Principios y estrategias operativas. Barcelona, ES: Gedisa.

Pratas, S. I. S. (2012). Guarda partilhada: estudo exploratório (Dissertação de Mestrado). Universidade de Coimbra, Coimbra, Portugal.

Trindade, J \& Molinari, F. (2015). Temas de Psicologia Forense. Porto Alegre, RS: Imprense livre.

Resolução $n^{\circ} 125$, de 29 de novembro de 2010. Dispõe sobre a Política Judiciária Nacional de tratamento adequado dos conflitos de interesses no âmbito do Poder Judiciário e dá outras providências. Recuperado de https://atos.cnj.jus.br/atos/detalhar/atosnormativos?documento $=156$

Rezende, J. C. O. (2015). Da judicialização à psicologização dos conflitos: A presença da psicologia na mediação dos conflitos
(Dissertação de Mestrado). Universidade de São Paulo, São Paulo, SP, Brasil.

Rudd, B. N., Hotzworth-Munroe, A., Applegate, A. G., D'Onofrio, B. M., Ballard, R. H., \& Bates, J. E. (2015a). Associations between parent and child reports of interparental conflict/violence and child difficulties in a family mediation setting. Family Court Review, 53(4), 602616. doi: 10.1111/fcre.12176

Rudd, B. N., Ogle, R. K., Holtzworth-Munroe, A., Applegate, A. G., \& D'Onofrio, B. M. (2015b). Child-informed mediation study follow-up: Comparing the frequency of relitigation following different types of family mediation. Psychology, Public Policy, and Law, 21(4), 452- 457. doi: 10.1037/law0000046

Rosenberg, M. B. (2006). Comunicação nãoviolenta: técnicas para aprimorar relacionamentos pessoais e profissionais. São Paulo, SP: Editora Agora.

Sales, L. M. M., \& Chaves, E. C. C. (2014). Mediação e conciliação judicial: a importância da capacitação e de seus desafios. Seqüência: estudos jurídicos e políticos, 35(69), 255-280. Recuperado de https://dialnet.unirioja.es/servlet/articulo?co $\underline{\operatorname{dig} O}=4934138$

Serrano, G. (2008). Eficacia y mediación familiar. Boletín de Psicología, 92, 51-63. Recuperado de https://www.uv.es/seoane/boletin/previos/N 92-3.pdf

Shine, S (2010). A espada de Salomão: A psicologia e a disputa de guarda de filhos. São Paulo, SP: Casa do Psicólogo.

Souza Neto, Z. G., D’Ávila, M. M., \& Honorato, B. G. (2018). O conflito familiar atendido em mediação judicial. In E. C. Batista, \& Z. G. Souza Neto, Interdisciplinaridade em psicologia na Amazônia: saúde, educação e sociedade (pp. 39-51). Curitiba, PR: Editora CRV. Spengler, F. M., \& Marcântonio, R. (2013). A Mediação como forma de tratamento de conflitos decorrentes da guarda de filhos. Revista Brasileira de Direito, IMED, 9(1), 78-97. doi: $10.18256 / 2238-$ 0604/revistadedireito.v9n1p78-97 
Teixeira, A. T. J., Froes, R. C., \& Zago, E. C. (2012). A comunicação e o relacionamento da família atual em virtude dos novos tempos. Revista eletrônica de comunicação, 1(1), 1-7. Recuperado de http://periodicos.unifacef.com.br/index.php /rec/article/view/422

Villaluenga, L. G., \& Cartujo, I. (2010). La família dialoga y llega a acuerdo: Mediacion familiar. Recuperado de http://www.madrid.org/bvirtual/BVCM007 215.pdf

\section{Dados sobre as autoras:}

- Zeno Germano de Souza Neto: Doutor em Psicologia pela Pontifícia Universidade Católica do Rio Grande do Sul (DINTER com a Faculdade Católica de Rondonia) com linha de pesquisa em Psicologia Jurídica/Mediação de conflitos familiares. Mestre em Estudos Literários pela Universidade de Rondonia. Especialista em Psicologia Clínica e Psicologia Jurídica pelo Conselho Federal de Psicologia. Especialista em Direito de Família pela Faculdade Católica de Rondonia. Especialista em Metodologia de Ensino pela Faculdade de Educação de Colorado do Oeste (RO). Graduado em Psicologia pela Universidade Federal de Rondônia (1999) é psicólogo das Varas de Família do Tribunal de Justiça de Rondônia, mediador de conflitos e psicoterapeuta psicanalítico.

- Milena Nardini Bubols: Possui Graduação em Psicologia (PUCRS). É Especialista em Psicologia Transpessoal pela Universidade Internacional da Paz (UNIPAZ). É Mestre em Psicologia Social e da Personalidade e doutoranda em Psicologia Clínica (PUCRS). É membro do Grupo de Pesquisa em Avaliação, Reabilitação e Intervenção Humano-Animal (ARIHA) do Programa de Pós-Graduação em Psicologia da PUCRS.

- Tatiana Quarti Irigaray: Bolsista produtividade nível 2 do CNPq. É graduada em Psicologia pela Universidade Federal do Rio Grande do Sul (UFRGS). Possui especialização em Psicologia Clínica com ênfase em Avaliação Psicológica e Neuropsicologia pela UFRGS. Realizou um Aperfeiçoamento em Neuropsicologia (Fellowship) no Hospital de Clínicas de Porto Alegre. É Doutora e Mestre em Gerontologia Biomédica pela Pontifícia Universidade Católica do Rio Grande do Sul (PUCRS). Tem Pós-Doutorado em Psicologia pela PUCRS. Atualmente é Decana Associada e Professora Adjunta dos Cursos de Graduação e PósGraduação em Psicologia da Escola de Ciências da Saúde da PUCRS. Também é Coordenadora do grupo de pesquisa Avaliação, Reabilitação e Interação Homem-Animal (ARIHA).

\section{Agências de fomento:}

CNPq, CAPES, FAPERGS.

\footnotetext{
Declaração de Direito Autoral

A submissão de originais para este periódico implica na transferência, pelos autores, dos direitos de publicação impressa e digital. Os direitos autorais para os artigos publicados são do autor, com direitos do periódico sobre a primeira publicação. Os autores somente poderão utilizar os mesmos resultados em outras publicações indicando claramente este periódico como o meio da publicação original. Em virtude de sermos um periódico de acesso aberto, permite-se o uso gratuito dos artigos em aplicações educacionais e científicas desde que citada a fonte conforme a licença CC-BY da Creative Commons.
} 